\title{
Escarro induzido em crianças e adolescentes com asma: segurança, aplicabilidade clínica e perfil de células inflamatórias em pacientes estáveis e durante exacerbação
}

\author{
Induced sputum in children and adolescents with asthma: safety, clinical applicability \\ and inflammatory cells aspects in stable patients and during exacerbation \\ Addy L. M. Palomino' ${ }^{1}$, Maria Helena C. F. Bussamra1, Beatriz M. Saraiva-Romanholo1, \\ Milton A. Martins ${ }^{2}$, Maria do Patrocínio T. Nunes ${ }^{3}$, Joaquim C. Rodrigues ${ }^{3}$
}

\section{Resumo}

Objetivos: Verificar a segurança da indução de escarro em crianças e adolescentes asmáticos. Caracterizar a citologia do escarro durante a estabilidade clínica e exacerbação. Correlacionar a citologia do escarro com os eosinófilos no sangue periférico, IgE sérica e grau de obstrução brônquica.

Métodos: Foram recrutados 96 pacientes asmáticos, de 6 a 18 anos, para um estudo transversal. Foi realizada espirometria antes e, após, broncodilatador. A seguir, foi coletado o escarro, espontaneamente ou após indução com inalação de solução salina em concentrações crescentes. Foi coletada amostra de sangue para quantificar a IgE sérica e os eosinófilos.

Resultados: Obtiveram-se amostras adequadas de escarro para análise em $68(70,8 \%)$ dos pacientes recrutados. Não houve broncoconstrição relevante durante a indução. A presença de maior número de eosinófilos no escarro de acordo com a maior gravidade clínica da asma não foi estatisticamente significante. Não houve correlação entre o grau de obstrução brônquica medido pelo $\operatorname{VEF}_{1}$ e as células inflamatórias do escarro. O mesmo foi observado em relação aos eosinófilos no sangue periférico e à IgE sérica. No grupo com exacerbação da asma, observouse uma quantidade maior de neutrófilos $(p<0,05)$.

Conclusões: A indução de escarro mostrou-se segura para obtenção de amostras clínicas em crianças e adolescentes, mesmo durante exacerbações, respeitando-se limitações clínicas e funcionais. 0 índice de sucesso da indução de $67 \%$ foi considerado satisfatório. A quantificação dos eosinófilos não discriminou a gravidade clínica e funcional da asma e mostrou-se independente do grau de obstrução das vias aéreas neste grupo de pacientes em tratamento com corticosteróides inalatórios. No escarro de pacientes em exacerbação da asma, houve um predomínio proporcional de neutrófilos.

J Pediatr (Rio J). 2005;81(3):216-24: Asma, solução salina hipertônica, escarro, criança, adolescência.

1. Mestre em Medicina pela Faculdade de Medicina, Universidade de São Paulo (FMUSP), São Paulo, SP.

2. Doutor em Medicina. Professor titular de Clínica Geral, Departamento de Clínica Médica, Faculdade de Medicina, FMUSP, São Paulo, SP.

3. Doutor em Medicina pela Faculdade de Medicina, FMUSP, São Paulo, SP.

Artigo submetido em 24.08.04, aceito em 03.02.05.

Como citar este artigo: Palomino AL, Bussamra MH, Saraiva-Romanholo BM, Martins MA, Nunes MP, Rodrigues JC. Escarro induzido em crianças e adolescentes com asma: segurança, aplicabilidade clínica e perfil de células inflamatórias em pacientes estáveis e durante exacerbação. J Pediatr (Rio J). 2005;81:216-24.

\section{Abstract}

Objectives: To determine the safety of sputum induction in asthmatic children and adolescents, to characterize sputum inflammatory cells while clinically stable and during exacerbation and to correlate sputum inflammatory cells with peripheral blood eosinophils, serum IgE and the degree of bronchial obstruction.

Methods: Ninety-six asthmatic patients aged 6 to 18 years were recruited for the present cross-sectional study. Spirometry was performed before and after administration of a bronchodilator. Sputum was collected spontaneously or after induction by the inhalation of saline solution at increasing concentrations. Blood samples were obtained for serum IgE and eosinophil quantification.

Results: Sputum samples adequate for analysis were obtained from $68(70.8 \%)$ of the patients recruited. No relevant bronchoconstriction was observed during induction. The presence of a larger number of eosinophils in sputum did not correlate with more clinically severe asthma. No correlation was observed between the degree of bronchial obstruction, measured based on $\mathrm{FEV}_{1}$, and inflammatory cells in sputum, peripheral blood eosinophils or serum IgE. Larger numbers of neutrophils were observed in the asthma exacerbation group $(p<0.05)$

Conclusions: Sputum induction was found to be a safe procedure for obtaining clinical samples from children and adolescents even during exacerbations, allowing for clinical and functional limitations. The $67 \%$ induction success rate was considered satisfactory. In this group of patients, receiving inhaled corticosteroids, eosinophil quantification did not distinguish between the clinical and functional severity of asthma and was independent of the degree of airway obstruction. A proportional predominance of neutrophils was observed in the sputum of patients with asthma exacerbation.

J Pediatr (Rio J). 2005;81(3):216-24: Asthma, sputum cell count, children.

\section{Introdução}

A asma é uma doença inflamatória crônica das vias aéreas, que resulta em obstrução variável ao fluxo aéreo e hiperresponsividade brônquica ${ }^{1}$. Várias células estão envolvidas nesse processo inflamatório, particularmente linfócitos, neutrófilos, mastócitos, eosinófilos e células epiteliais. Os eosinófilos produzem proteínas citotóxicas e leucotrienos, que têm a capacidade de lesar o epitélio das vias aéreas e ainda constituem um fator de perpetuação do recrutamento celular ${ }^{2}$. Os neutrófilos parecem exercer um papel mais 
relevante nas exacerbações, na asma noturna, na asma de difícil controle e na asma grave não-responsiva a corticosteróides, e sugere-se a sua participação no remodelamento das vias aéreas ${ }^{3}$.

A intensidade do processo inflamatório pode ser avaliada direta ou indiretamente. A biópsia brônquica e o lavado bronco-alveolar foram utilizados para analisar os padrões de resposta celular relacionados à gravidade clínica, subtipos celulares, ativação e expressão de células inflamatórias, produção de citocinas e de mediadores da resposta inflamatória mediada pelos eosinófilos ${ }^{4}$. No entanto, são procedimentos invasivos que não podem ser aplicados para monitorização rotineira do processo inflamatório, particularmente em crianças. Nos últimos anos, tem-se buscado marcadores da atividade inflamatória em asmáticos empregando-se técnicas pouco invasivas, como a medida do óxido nítrico no ar exalado e a celularidade do escarro.

O escarro pode ser obtido espontaneamente ou por indução com inalação de solução salina hipertônica $(\mathrm{SSH})^{4,5}$. $\mathrm{O}$ exame do escarro induzido tem-se mostrado um método seguro e com potencialidade de caracterizar a intensidade e a evolução do processo inflamatório. No entanto, as peculiaridades dos achados de citologia nos diferentes graus de intensidade da asma e as diferenças entre os períodos de estabilidade e exacerbação da asma não foram completamente avaliadas em crianças.

Os objetivos deste estudo foram: 1) verificar a segurança e aplicabilidade clínica da indução de escarro em crianças e adolescentes com asma; 2) caracterizar a celularidade do escarro num grupo de pacientes com asma de gravidade variável durante período de estabilidade clínica e em pacientes com exacerbação; 3) correlacionar a celularidade do escarro com o grau de obstrução brônquica, o número de eosinófilos no sangue periférico e a dosagem de IgE sérica total.

\section{Casuística e métodos}

Foram recrutados 96 crianças e adolescentes com diagnóstico de asma ${ }^{1}$, acompanhados regularmente nos Ambulatórios de Pneumologia e Imunologia do Instituto da Criança do Hospital das Clínicas da Faculdade de Medicina da Universidade de São Paulo, que eram encaminhados ao laboratório de testes de função pulmonar para realização de espirometria de rotina. Foram incluídos pacientes de 6 a 18 anos, com diferentes gravidades clínicas $^{1}$, capazes de executar espirometria. Foram excluídos pacientes com infecções pulmonares de repetição, alterações radiológicas persistentes ou qualquer dado sugestivo de outra doença pulmonar. Foi considerado estável o paciente sem exacerbação da doença e sem episódios infecciosos nas últimas 4 semanas que antecederam a realização dos testes. Foi considerado com exacerbação da asma o paciente que comparecia para realizar espirometria, mas que, por relato dos pais e/ou avaliação clínica, tinha sinais de exacerbação da doença, como tosse e/ou dispnéia e/ou sibilância. Para classificação da gravidade da asma, aplicou-se um breve questionário para obtenção de dados clínicos (sintomas e terapêutica atual) e utilizou-se a medida do volume expiratório forçado no primeiro segundo $\left(V_{E F}\right)$ pré-broncodilatador.

A espirometria foi realizada segundo recomendações técnicas internacionais ${ }^{6}$, utilizando-se espirômetro de campânula (Warren Collins, Inc, MA, EUA). Os valores obtidos da capacidade vital forçada (CVF) e do $V_{E F}$ foram expressos em porcentagem dos valores previstos, segundo as equações de Polgar \& Promadhat ${ }^{7}$. Quinze minutos após a administração de $400 \mu \mathrm{g}$ de salbutamol aerossol, foi repetida a espirometria. A resposta ao broncodilatador (BD) foi considerada significativa quando houve aumento do $V_{E F}$ maior ou igual a $7 \%$, em relação ao previsto ${ }^{8}$. Antes da realização das espirometrias basal e após BD, foi efetuada a medida do pico de fluxo expiratório (PFE) com medidor de pico de fluxo (Peak Flow Meter Mini- Wright, Clement Clark International).

\section{Indução e processamento do escarro}

Após realização de espirometria, foi solicitado aos pacientes para tossir e escarrar num pote estéril de polipropileno. No caso de obtenção de uma amostra suficiente para análise, a indução não era realizada. A indução do escarro com SSH seguiu a metodologia descrita por Pizzichini ${ }^{9}$, modificando-se apenas o nebulizador empregado. Utilizouse compressor Proneb e nebulizador Pari com peça bucal portando válvula expiratória, fluxo de $0,87 \mathrm{ml} / \mathrm{min}$ e emissão de partículas de aproximadamente $6 \mu \mathrm{m}$. Os pacientes estáveis com $\mathrm{VEF}_{1}$ maior ou igual a $50 \%$ do previsto realizaram nebulizações com SSH, com clipe nasal, durante 10 minutos para cada concentração de 3, 4 e 5\%. O tempo máximo de nebulização previsto foi de 30 minutos para coleta de, pelo menos, $0,5 \mathrm{ml}$ de escarro. Os pacientes estáveis com $\mathrm{VEF}_{1}<50 \%$ do previsto ou em exacerbação receberam nebulizações somente com solução salina fisiológica (SSF). Medidas de PFE e ausculta pulmonar foram realizadas imediatamente após cada nebulização. A presença de dispnéia, sibilância e/ou queda do PFE > 20\% em relação ao inicial foi considerado motivo para suspensão do procedimento de indução e administração de $200 \mu \mathrm{g}$ de salbutamol inalatório. A queda do PFE entre 10 e $20 \%$ não contra-indicou a administração de nova nebulização, porém foi mantida a mesma concentração salina. Variações do PFE < $10 \%$ permitiram a realização da nebulização com a concentração de SSH seguinte. Após cada nebulização, foi solicitado ao paciente para assoar o nariz e enxaguar a boca com água para evitar a contaminação com saliva e, na seqüência, tossir e escarrar no frasco ${ }^{10}$. O frasco contendo o escarro foi mantido em caixa de isopor com gelo, e o material foi processado em até 2 horas após a coleta. Todos os procedimentos foram seguidos por um dos médicos pesquisadores, tendo à disposição no laboratório, caso necessário, materiais e medicamentos de urgência.

O material coletado foi colocado numa placa de Petri, e foi separado o escarro da saliva com uma pipeta de polipropileno. O processamento da amostra seguiu a metodologia descrita por Pizzichini ${ }^{9}$. A viabilidade e a contagem celular total foram verificadas na câmara de Neubauer e sob 
microscopia óptica, considerando-se, no máximo, 50\% de células não-viáveis e $80 \%$ de células escamosas. Para o preparo dos cytospins, utilizou-se a centrífuga Shandom III (Shandom Southern Instruments, Sewickley, PA, EUA), centrifugando-se a $450 \mathrm{rpm}$ durante 6 minutos. As lâminas foram coradas com Leishman ${ }^{11}$. Foram lidas uma ou duas lâminas até a contagem de 400 células não-escamosas e não-metacromáticas, referindo-se os dados diferenciais em termos de porcentagem.

Na mesma data, imediatamente após o procedimento de indução, foi coletada amostra de sangue para dosagem de IgE sérica total e leucograma apenas nos pacientes em que foi obtida amostra de pelo menos $0,5 \mathrm{ml}$ de escarro.

O protocolo foi aprovado pelo Comitê de Ética para Análise de Projetos de Pesquisa do Hospital das Clínicas da Faculdade de Medicina da Universidade de São Paulo. Os pacientes e responsáveis foram informados e consentiram em participar do estudo

\section{Análise estatística}

Para a análise descritiva, foram empregados cálculos de média e desvio padrão, determinação da mediana e percentis, dependendo da variável estudada. Foi utilizada a correlação de Spearman ou de Pearson, de acordo com a distribuição dos dados, considerando-se significantes os coeficientes $(r)$ maiores que 0,50 e $p<0,01$.

\section{Resultados}

Foram recrutados 96 pacientes asmáticos na faixa etária entre 6 a 18 anos. Em 10 pacientes, o escarro foi obtido espontaneamente, e os 86 pacientes restantes foram submetidos ao procedimento de indução de escarro. A indução do escarro falhou em obter material ou a amostra foi inadequada em 28 pacientes (índice de sucesso $=67 \%$ ). O grupo de estudo constituiu-se, então, de 68 pacientes.

A média de idade foi de 10,5 anos, sendo que 48 pacientes $(70,5 \%)$ tinham entre 6 e 11 anos. Quanto ao sexo, $27(39,7 \%)$ eram do sexo feminino e $41(60,2 \%)$ do sexo masculino (proporção $M: F \quad 1: 1,5$ ). Os pacientes estáveis foram agrupados segundo a gravidade da asma: 11 pacientes $(18,3 \%)$ tinham asma leve (intermitente ou persistente); 20, asma moderada (33\%) e 29, asma grave $(48,3 \%)$. O grupo em exacerbação da asma constitui-se de oito pacientes. As características clínicas e funcionais dos grupos estão representadas na Tabela 1 . 0 grupo de pacientes com asma grave apresentou valores de $V_{E F}$ reduzidos em relação aos grupos de asma leve e moderada ( $p<0,001$ e $p=0,003$, respectivamente). 0 grupo de pacientes em exacerbação da asma também apresentou essa redução do $\mathrm{VEF}_{1}$ quando comparado aos grupos de asma leve e moderada $(p<0,001)$. A resposta ao BD foi observada com maior freqüência no grupo com asma grave $(p<0,05)$.

Tabela 1 - Características das crianças e adolescentes com asma, segundo a gravidade da asma ${ }^{1}$, parâmetros funcionais e laboratoriais

\begin{tabular}{|c|c|c|c|c|c|}
\hline & Leve * & Moderada & Grave & $\begin{array}{l}\text { Exacerbação } \\
\text { asmática }\end{array}$ & $\mathbf{p}$ \\
\hline Pacientes (n) & 11 & 20 & 29 & 8 & - \\
\hline Sexo F/M & $4 F / 7 M$ & $8 \mathrm{~F} / 12 \mathrm{M}$ & $13 \mathrm{~F} / 16 \mathrm{M}$ & $2 F / 6 M$ & - \\
\hline Idade (anos), média \pm DP & $9,8 \pm 2,6$ & $9,9 \pm 2,2$ & $11,4 \pm 3$ & $10 \pm 1,6$ & - \\
\hline Em uso de CE inalatório & $3(27 \%)$ & $13(65 \%)$ & $24(83 \%)$ & $7(87 \%)$ & - \\
\hline $\mathrm{VEF}_{1} \%$ pré, média $\pm \mathrm{DP}$ & $102,4 \pm 8,4$ & $90,5 \pm 13,5$ & $\begin{array}{c}72,4 \pm 13,7 \\
\vdots \S\end{array}$ & $\begin{array}{c}70 \pm 16,2 \\
+\neq\end{array}$ & $\begin{array}{l}{ }_{p} p<0,001 \\
p<<0,001 \\
\S p<0,001 \\
p=0,003\end{array}$ \\
\hline $\mathrm{VEF}_{1} / \mathrm{CVF} \%$, média $\pm \mathrm{DP}$ & $88,4 \pm 5,6$ & $83,2 \pm 5,5$ & $\begin{array}{c}73,3 \pm 1,6 \\
: \S\end{array}$ & $77,8 \pm 10,9$ & $\begin{array}{l}\S p<0,05 \\
p<0,05\end{array}$ \\
\hline$n$, resposta $B D>7 \%$ & $1 / 11(9 \%)$ & $6 / 20(30 \%)$ & $\begin{array}{c}20 / 29(69 \%) \\
\S\end{array}$ & $6 / 8(75 \%)$ & $\S p<0,05$ \\
\hline IgE UI/ml M (min-máx) & $\begin{array}{c}1.037 \\
(331-3.428)\end{array}$ & $\begin{array}{c}771 \\
(259-14.940)\end{array}$ & $\begin{array}{c}989 \\
(29-11.110)\end{array}$ & $\begin{array}{c}365 \\
(30-1.833)\end{array}$ & NS \\
\hline Eos sangue $M$ (min-máx) & $\begin{array}{c}546 \\
(103-1.003)\end{array}$ & $\begin{array}{c}616 \\
(192-1.278)\end{array}$ & $\begin{array}{c}510 \\
(82-1.760)\end{array}$ & $\begin{array}{c}431 \\
(237-620)\end{array}$ & NS \\
\hline
\end{tabular}

$\mathrm{DP}=$ desvio padrão; $\mathrm{CE}$ = corticosteróide $\mathrm{BD}$ = broncodilatador IgE = imunoglobulina $\mathrm{E}$ sérica; Eos = eosinófilos; $\mathrm{M}=$ mediana com os dados mínimos e máximos; NS = não significativo.

* O grupo asma leve compreende os pacientes com asma leve intermitente e persistente devido ao $V_{E F}>80 \%$.

$V_{E F} \dagger p<0,001$ entre o grupo com exacerbação e o de asma leve.

$\ddagger \mathrm{p}<0,001$ entre o grupo com exacerbação e o de asma moderada.

$\S \mathrm{p}<0,001$ entre o grupo com asma grave e leve.

$\mathrm{VEF}_{1} / \mathrm{CVF} \S \mathrm{p}<0,05$ entre o grupo com asma grave e leve.

$\mathrm{p}<0,05$ entre o grupo com asma grave e moderada. 
A dosagem da IgE sérica total mostrou-se elevada para a faixa etária em 62 pacientes (91\%), e 47 (70\%) apresentaram eosinofilia periférica acima de $5 \%$. Esses achados não estiveram correlacionados à gravidade da asma.

O tempo médio de inalação para indução do escarro foi de $18 \pm 7,8$ minutos. Houve queda do PFE em relação ao valor basal de $10 \%$ em cinco pacientes $(7,35 \%)$, entre 10 e $20 \%$ em três $(4,4 \%)$ e $>20 \%$ em dois (3\%). Nesses pacientes com critério para interrupção do procedimento de indução do escarro, a broncoconstrição foi prontamente revertida com BD e não houve complicação clinicamente detectável.

$O$ volume do escarro obtido variou entre 0,5 e $5 \mathrm{ml}$. A média de porcentagem de células viáveis foi de $74( \pm 16)$ e de células escamosas, 21,62 ( $\pm 22,2)$.

A Tabela 2 mostra a contagem celular total e a celularidade diferencial nos diferentes grupos de pacientes. Não houve diferenças entre percentual médio de eosinófilos nos três grupos de pacientes com asma estável. Os pacientes estáveis em uso de corticosteróides inalatórios apresentaram eosinófilos de 10,48\% em média e, naqueles sem corticoterapia, esse valor foi de $9,51 \%(p>0,05)$ (Tabela 3$)$. Notou-se uma grande variabilidade do percentual de eosinófilos de toda a população estudada, e $60 \%$ dos pacientes estáveis recebiam corticosteróide inalatório e ainda apresentavam percentual de eosinófilos no escarro acima de 2,5\%.

Observou-se um predomínio de neutrófilos no grupo de pacientes em exacerbação da asma quando comparado aos demais grupos $(p<0,05)$. A variação do percentual de eosinófilos e neutrófilos nos diferentes grupos é melhor visualizada nas Figuras 1 e 2, respectivamente.

A Figura 3 mostra a dispersão da correlação entre a porcentagem de eosinófilos no escarro e os valores de $V F_{1}$ de todos os pacientes do estudo. Considerou-se que não houve correlação entre a quantificação de eosinófilos no escarro e o grau de obstrução brônquica verificado na função pulmonar $(r=0,118$ e $p=0,336)$. A mesma análise de correlação foi feita para a contagem das demais células do escarro (linfócitos, macrófagos e neutrófilos), e os resultados foram semelhantes.

Tabela 2 - Celularidade do escarro por grupos de gravidade. Contagem celular total e diferencial, valores expressos em média $\pm D P$

\begin{tabular}{|c|c|c|c|c|c|}
\hline & Leve * & Moderada & Grave & $\begin{array}{c}\text { Exacerbação } \\
\text { asmática }\end{array}$ & $\mathbf{p}$ \\
\hline Cel $\times 10^{6} / \mathrm{ml}$ & $2,2 \pm 2,4$ & $1,6 \pm 1,7$ & $1,4 \pm 1,4$ & $5 \pm 4$ & NS \\
\hline \% eosinófilos & $4,9 \pm 4,8$ & $8,4 \pm 13,5$ & $12,6 \pm 21,1$ & $0,7 \pm 1$ & NS \\
\hline \% neutrófilos & $35,7 \pm 23 *$ & $47,2 \pm 24,1 *$ & $44,8 \pm 29,8 *$ & $80,8 \pm 13,2 *$ & $* p<0,05$ \\
\hline \% macrófagos & $48,8 \pm 20,9^{\dagger}$ & $37,1 \pm 23$ & $38,4 \pm 29,6$ & $13,6 \pm 9,3^{+}$ & ${ }^{+} p<0,05$ \\
\hline \% linfócitos & $1,28 \pm 2,5$ & $1,14 \pm 2,9$ & $0,32 \pm 0,8$ & 0 & NS \\
\hline \% células epiteliais & $0,8 \pm 0,2$ & $2,1 \pm 0$ & $0,28 \pm 0$ & $1,63 \pm 0$ & NS \\
\hline
\end{tabular}

DP = desvio padrão; Cel = células; NS = não significativo.

* $p<0,05$ para o grupo em exacerbação em relação ao grupo de asma leve, moderada e grave.

$\dagger * p<0,05$ para o grupo em exacerbação em relação ao grupo de asma leve.

Tabela 3 - Celularidade do escarro por grupos de gravidade, segundo o tratamento com corticosteróides inalatórios (CI). Valores expressos em média \pm DP ou mediana (p25-p75)

\begin{tabular}{|c|c|c|c|c|c|c|c|}
\hline & \multicolumn{2}{|c|}{ Leve } & \multicolumn{2}{|c|}{ Moderada } & \multicolumn{2}{|c|}{ Grave } & \multirow[t]{2}{*}{$\mathbf{p}$} \\
\hline & Com CI & Sem CI & Com CI & Sem CI & Com CI & Sem CI & \\
\hline$\%$ eosinófilos & $6,97 \pm 5,5$ & $3,74 \pm 5,3$ & $2,6(1,1-9,3)$ & $3,5(0-6,9)$ & $5(0,6-13,1)$ & $2,5(0-27)$ & NS \\
\hline$\%$ neutrófilos & $34,5 \pm 25,8$ & $36,8 \pm 28,8$ & $47,8 \pm 21,6$ & $48,9 \pm 31,9$ & $43,6 \pm 30,5$ & $52,5 \pm 27,6$ & NS \\
\hline
\end{tabular}




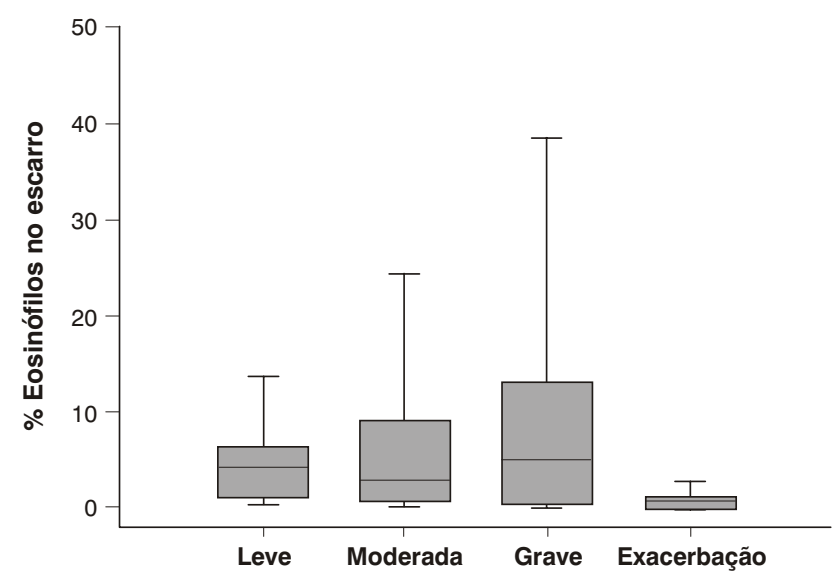

Figura 1 - Distribuição dos eosinófilos (\%) do escarro induzido dos grupos com asma de diferentes gravidades $\mathrm{p}=\mathrm{NS}$

\section{Discussão}

Neste estudo, foi descrita a celularidade do escarro, obtido espontaneamente ou após indução com SSH, de crianças e adolescentes com asma de diferentes gravidades, no período de estabilidade da doença e durante as exacerbações.

Como a técnica de indução foi introduzida na rotina do laboratório de função pulmonar do Instituto da Criança com a realização deste estudo, o objetivo inicial foi verificar se a mesma era factível e segura com as adaptações necessárias à nossa realidade. A indução de escarro foi bem sucedida em $67,4 \%$ das vezes. Estudos envolvendo casuís- ticas semelhantes referiram percentuais de sucesso na obtenção de escarro em $56 \%{ }^{12}, 84 \%^{13}$ e $95 \%{ }^{14}$. Segundo Paggiaro ${ }^{15}$, a obtenção de amostras adequadas de escarro está mais relacionada às características individuais dos pacientes do que a fatores técnicos durante a coleta do material.

O tipo de nebulizador utilizado pode influenciar no sucesso da indução, sendo o nebulizador ultrassônico De Vilbiss o que produz maiores fluxos e maiores volumes de escarro. Por outro lado, os nebulizadores de baixo fluxo (abaixo de $1 \mathrm{ml} /$ minuto) causam menos desconforto respiratório do que os de alto fluxo, o que pode ser mais

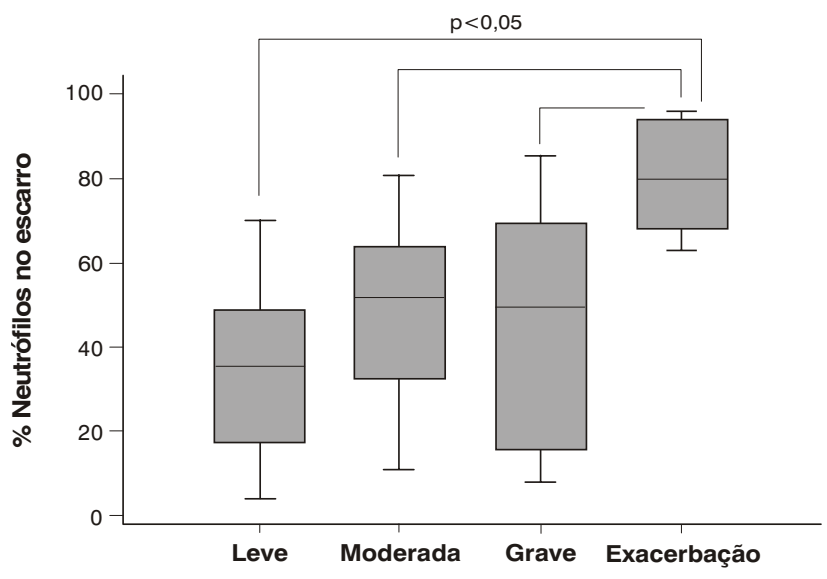

Figura 2 - Distribuição dos neutrófilos (\%) do escarro induzido dos grupos com asma de diferentes gravidades. $p<0,05$ em relação ao grupo com exacerbação e cada grupo de asma estável 


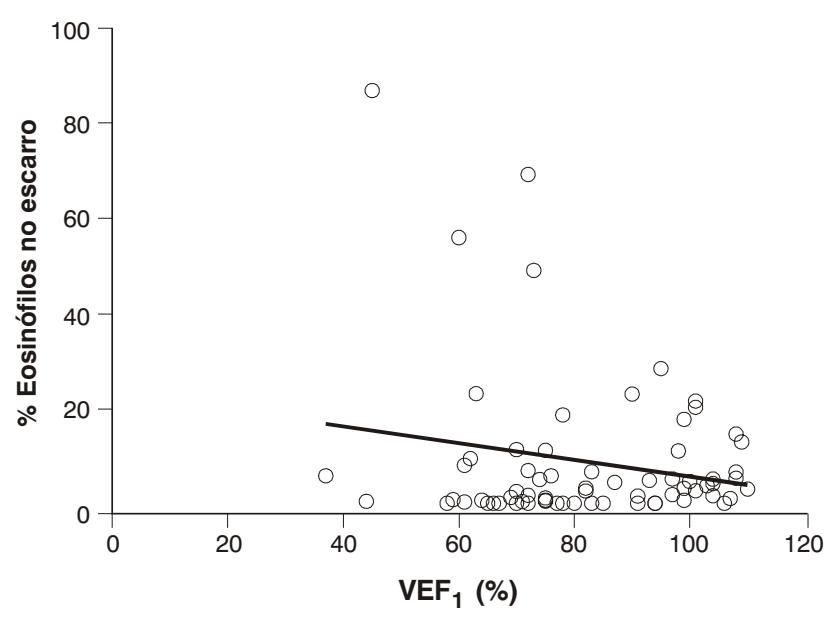

Figura 3 - Dispersão da correlação entre a porcentagem de eosinófilos do escarro e o $\operatorname{VEF}_{1}$ (\% do predito) das 68 crianças com asma de diferente gravidade. $r=0,118$ e $p=0,336$

adequado para a utilização em crianças ${ }^{16,17}$. No presente estudo, foi utilizado nebulizador de baixo fluxo Proneb-Pari, disponível no laboratório e melhor adaptado à faixa etária avaliada, sem comprometer o sucesso do procedimento.

Não há diferença na contagem celular quando se utiliza nebulização com SSF ou SSH para indução do escarro, independentemente da gravidade da asma16. Porém, a indução é mais bem sucedida com SSH do que com SSF ${ }^{17}$. No entanto, a SSF é mais segura e melhor tolerada em pacientes com asma grave ${ }^{18}$. Neste estudo, visando maior segurança, realizamos a indução com SSF ou SSH, dependendo da gravidade clínica e funcional de cada paciente. Ressalta-se que, dessa forma, não houve complicações relacionadas ao procedimento de indução.

Fahy et al. ${ }^{19}$ observaram, em estudo multicêntrico, que, independentemente da gravidade clínica e funcional, alguns pacientes eram mais hiper-reativos à SSH, induzindo broncoespasmo mesmo com o uso prévio de BD. Também verificaram, nesses pacientes, quedas no $\mathrm{VEF}_{1}$ entre 40 e $60 \%$ cerca de 4 minutos após o inicio da indução com SSH. Nesse estudo, observou-se que, no total, 6,8\% dos pacientes tiveram queda no PFE. Em nosso estudo, apenas dois pacientes apresentaram broncoconstrição notada como queda de $20 \%$ do $\mathrm{PFE}$, que foi prontamente revertida com $\mathrm{BD}$, sem necessidade de internação ou encaminhamento ao serviço de emergência.

Em relação ao tempo de indução do escarro, o tempo médio foi de 18 minutos, $75 \%$ dos pacientes produziram escarro entre 10 e 20 minutos, e $21 \%$ necessitaram de 30 minutos. O consenso internacional considera como tempo adequado 15 a 20 minutos de indução. Dessa maneira, diferentes compartimentos da via aérea celulares são amostrados em relação ao tempo cumulativo de indução. Assim, nos minutos iniciais, são amostrados os componentes da via aérea central com predomínio de neutrófilos, e, nos minutos finais, as vias aéreas distais e o compartimento alveolar, havendo o predomínio de macrófagos ${ }^{20,21}$.

A qualidade do material a ser analisado depende do tempo para início do processamento do escarro, do número de células escamosas presentes na amostra e da quantidade de células inflamatórias analisadas ${ }^{16}$. Idealmente, sugere-se que o escarro seja processado em até 2 horas após a coleta $^{22}$. Recomenda-se a separação da saliva, pois quanto menor o número de células escamosas, tanto melhor é a qualidade das lâminas e mais fácil a identificação das células inflamatórias. Devem-se contar, no mínimo, 400 células inflamatórias, e recomenda-se a leitura de até cinco lâminas $^{23,24}$. A viabilidade celular abaixo de $50 \%$ e a contaminação com células escamosas acima de $20 \%$ tornam o método menos reprodutível, mas pode-se aceitar amostras de escarro com até $80 \%$ de células escamosas 4,19 . Em nosso estudo, apesar de todos os cuidados com a coleta e separação do material, houve necessidade de leitura de mais de uma lâmina em $16 \%$ das amostras analisadas, pois na lâmina inicial havia entre 50 e $80 \%$ de células escamosas. Esse detalhe não interferiu com a qualidade dos resultados, porém prolongou ainda mais o tempo de processamento. O tempo de processamento, de cerca de 60 a 90 minutos por amostra de escarro, além do tempo de indução da produção do escarro, limita o número de exames a serem analisados em um único dia. Pode-se tentar armazenar o material a $4{ }^{\circ} \mathrm{C}$ até 9 horas após a coleta, sem que exista alteração na contagem celular total ou na diferencial22. A disponibilidade de tempo e pessoal especializado é algo a ser considerado quando se pretende a implantação dessa técnica como rotineira. 
Cai et al. demonstraram que o percentual máximo de eosinófilos no escarro de crianças normais é de $2,5 \% 25$. A eosinofilia no escarro também é uma característica da asma na população pediátrica, pode estar relacionada com a gravidade clínica da doença e reduz-se após corticoterapia 26 . Estima-se que mais do que $80 \%$ de asmáticos sem uso prévio de corticosteróides e mais de $50 \%$ dos que usam corticoterapia inalatória possam ter níveis de eosinófilos no escarro acima do normal ${ }^{27}$. Em nosso estudo, de maneira semelhante ao referido por Gibson 28 , observamos que $60 \%$ dos pacientes estáveis faziam uso de corticoterapia inalatória e tinham percentual de eosinófilos no escarro acima de 2,5\%.

Ainda não há recomendação fundamentada sobre qual conduta clínica a ser tomada nessa situação, onde há estabilidade clínica e funcional, porém demonstra-se a presença de marcadores de inflamação das vias aéreas. Green et al. propuseram uma estratégia para tratamento da asma onde o controle da doença estava baseado na manutenção da contagem de eosinófilos do escarro abaixo de 3\%. Quando comparado aos pacientes tratados segundo as recomendações atuais, de monitorização clínica e funcional, o grupo tratado segundo essa nova estratégia apresentou menor número de exacerbações e hospitalizações, menor necessidade de esteróides orais e menor custo global de tratamento ${ }^{29}$. A discussão sobre qual a melhor forma de monitorizar a evolução do tratamento do asmático e considerá-lo sob controle é bastante atual. Estratégias baseadas em marcadores de inflamação das vias aéreas requerem medidas seriadas e, nesse caso, contagens seriadas da celularidade do escarro. Ao utilizar uma técnica de indução cujo índice de sucesso está em torno de $70 \%$ na população pediátrica, podem existir sérias limitações quanto à obtenção regular de dados necessários para o seguimento dos pacientes.

Apesar de se observar um aumento progressivo do percentual de eosinófilos no escarro, de acordo com a maior gravidade da asma, essa diferença não foi significante entre os grupos. Isso pode ser explicado, em parte, porque a maioria das crianças estudadas usava corticosteróide inalatório, em doses médias e elevadas, por período superior a 3 meses. Estudos prévios demonstraram que esse período de tratamento, nessas dosagens, é suficiente para reduzir de maneira significativa o número de eosinófilos no escarro e que a redução da dose ou a suspensão do tratamento pode reativar o incremento de eosinófilos ${ }^{30}$. Bartoli et al. descreveram a celularidade do escarro em um grupo maior, de 223 pacientes asmáticos de gravidade variável e 14 indivíduos controles, e notaram que pacientes com asma persistente leve e moderada não diferem quanto à contagem de eosinófilos no escarro, independentemente do tratamento regular com corticosteróides inalatórios. Neste estudo, como esperado, o percentual de eosinófilos no escarro diferenciou adequadamente os pacientes asmáticos dos controles ${ }^{31}$.

Há relatos na literatura sugestivos de que a celularidade e outros marcadores de inflamação presentes no escarro estejam relacionados à gravidade da asma ${ }^{26}$. Por outro lado, resultados de estudos bem conduzidos contestam essa afirmação, e permanece controverso o real papel da celularidade do escarro em discriminar a gravidade da asma ${ }^{32}$. De fato, o próprio grupo de trabalho internacional sobre escarro induzido comenta que há uma fraca relação entre a gravidade da asma definida por função pulmonar ou sintomas e a contagem de eosinófilos no escarro e que mais estudos são necessários para definir a relação entre a inflamação das vias aéreas, os sintomas e a resposta aos corticosteróides em pacientes asmáticos ${ }^{33}$.

Em nosso estudo, apesar da redução significativa das médias do $\mathrm{VEF}_{1}$ no grupo de asmáticos graves, não houve correlação significativa entre a porcentagem de eosinófilos no escarro e o grau de obstrução brônquica. É importante salientar que utilizamos a classificação da gravidade clínica dos pacientes baseando-se não apenas em critérios clínicos e funcionais, mas considerando o tratamento prévio, conforme recomendação internacional ${ }^{1}$. Assim, alguns pacientes foram considerados graves porque usavam doses elevadas de corticosteróide inalado, apesar de manifestarem pouca obstrução pelo $V_{E F}$. Pin et al. ${ }^{4}$, estudando adultos e adolescentes, encontraram correlação significativa entre o percentual de eosinófilos no escarro e o grau de obstrução. Gibson et al., em publicação mais recente, estudaram 146 crianças com asma estável de diferentes gravidades e não observaram essa correlação, nem mesmo entre o percentual de eosinófilos do escarro e a responsividade brônqui$\mathrm{ca}^{32}$. Os autores justificaram esse achado pelo fato de que $94,5 \%$ das crianças tinham valores de $\mathrm{VEF}_{1}$ acima de $80 \%$ do previsto e, portanto, sem obstrução detectável, apesar de possuírem diferentes níveis de gravidade da asma baseados em critérios clínicos. No nosso estudo, 53,33\% tinham $V F_{1}$ acima de $80 \%$. Isso leva à conclusão de que, provavelmente, cada método fornece uma informação diferente a respeito da condição de doença do paciente, porém são complementares na caracterização dos diferentes aspectos do processo inflamatório da asma 5 .

Não houve correlação entre as alterações observadas no sangue periférico, eosinofilia e elevação de IgE sérica, e o percentual de eosinófilos no escarro. A grande variabilidade desses parâmetros em cada grupo estudado pode explicar, em parte, esse resultado. Os dados publicados a esse respeito sugerem que os eosinófilos no escarro constituem um marcador mais acurado da inflamação das vias aéreas, uma vez que os eosinófilos no sangue periférico podem estar aumentados em outras condições, como rinite e eczema, e não estar relacionados com a gravidade da asma².

Em relação à exacerbação da asma, há consenso sobre o importante aumento da celularidade total ${ }^{17,34}$, provavelmente devido ao maior influxo de células inflamatórias e conseqüente maior descamação do epitélio. O aumento do número total de células foi também verificado em nosso estudo, entre duas a quatro vezes em relação aos grupos estáveis. Entretanto, essa diferença não foi estatisticamente significante, provavelmente devido ao pequeno número de pacientes em exacerbação. Gibson et al. estudaram a celularidade do escarro de crianças em 
crise e encontraram três padrões: com eosinófilos, com eosinófilos e neutrófilos e o terceiro não-eosinofílico. Descreveram, ainda, que o grupo com maior porcentagem de eosinófilos foi aquele sem uso de tratamento antiinflamatório, ocorrendo o contrário naqueles em uso de corticosteróides orais, e um terço das crianças em crise teve aumento dos neutrófilos ${ }^{34}$. As viroses são potentes indutores de resposta neutrofílica e constituem causa freqüente de exacerbações de asma em crianças. Observou-se que o grupo em exacerbação teve os maiores níveis de neutrófilos ( $p=0,05)$ em relação a todos os grupos de asma estável. Entretanto, não foi realizada pesquisa etiológica para vírus respiratórios, pois não era o objetivo inicial da avaliação desse grupo de pacientes.

O procedimento de indução de escarro, inicialmente descrito para adultos, com inalação de solução salina em concentrações crescentes mostrou-se método seguro para obtenção de amostras clínicas em crianças e adolescentes, mesmo durante exacerbações, respeitando-se limitações clínicas e funcionais. A obtenção de amostra de escarro adequada para análise foi possível na maioria dos casos, e o índice de sucesso da indução de $67 \%$ é comparável aos dados de literatura. A quantificação dos eosinófilos no escarro não teve poder de discriminar a gravidade clínica e funcional da asma, porém o grupo de estudo estava sob tratamento com corticosteróides inalatórios. No escarro de pacientes em exacerbação da asma houve, proporcionalmente, predomínio de neutrófilos.

\section{Agradecimentos}

Agradecimentos à Sra. Cecília Marlene de Andrade, pela disponibilidade e competência na realização das espirometrias.

\section{Referências}

1. NHLBI/WHO. Global strategy for asthma management and prevention. In: Lenfant C. Global Initiative for Asthma. Bethesda: National Institute of Health. National Heart, Lung and Blood Institute; 2002.

2. Sampson AP. Eosinophils: provokers or bystanders in asthma? Clin Exp Allergy Rev. 2001;1:73-6.

3. Vignola AM, La Grutta S, Chiappara G, Benkeder A, Bellia V, Bonsignore $\mathrm{G}$. Cellular network in airways inflammation and remodelling. Pediatr Respir Rev. 2002;3:41-6.

4. Pin I, Gibson PG, Kolendowicz R, Girgis-Gabardo A, Denburg JA, Hargreave $F E$, et al. Use of induced sputum cell counts to investigate airway inflammation in asthma. Thorax. 1992;47: 25-9.

5. Wilson NM, James A, Uasul C, Payne DN, Hablas H, Agrofioti C, et al. Asthma severity and inflammations markers in children. Pediatr Allergy Immunol. 2001;12:125-32.

6. American Thoracic Society. Standardization of spirometry: 1994 update. Am J Respir Crit Care Med. 1995;152:1107-36.

7. Polgar G, Promadhat V. Pulmonary function testing in children. Philadelphia: WB Saunders; 1971. p. 273.

8. Rodrigues JC, Cardieri JMA, Bussamra MHCF, Nakaie CMA, Almeida MB, Silva Filho LVF, et al. Provas de função pulmonar em crianças e adolescentes. J Pneumol. 2002;28(Suppl 3): S207-21.

9. Pizzichini MMM. O exame do escarro como instrumento responsivo e adequado para investigar o efeito de drogas na inflamação das vias aéreas [tese]. São Paulo: Faculdade de Medicina da Universidade Federal de São Paulo; 1997.
10. Pizzichini MMM, Popov TA, Efthimiadis A, Hussack P, Evans $S$, Pizzichini $E$, et al. Spontaneous and induced sputum to measure indices of airway inflammation in asthma. Am J Respir Crit Care Med. 1996;154:866-9.

11. Saraiva-Romanholo BM, Barnabe V, Carvalho AL, Martins MA, Saldiva $\mathrm{PH}$, Nunes MP. Comparison of three methods for differential cell count in induced sputum. Chest. 2003;124: 1060-6.

12. Wilson NM, Bridge $P$, Spanevello $A$, Silverman $M$. Induced sputum in children: feasibility, repeatability, and relation of findings to asthma severity. Thorax. 2000;55:768-74.

13. Cai Y, Carty K, Henry RL, Gibson PG. Persistence of sputum eosinophilia in children with controlled asthma when compared with healthy children. Eur Respir J. 1998;11:848-53.

14. Grootendorst DC, van den Bos JW, Romeijn JJ, Veselic Charvat $M$, Duiverman EJ, Vrijlandt $E$, et al. Induced sputum in adolescents with severe stable asthma. Safety and the relationship of cell counts and eosinophil cationic protein to clinical severity. Eur Respir J. 1999;13:647-53.

15. Paggiaro $\mathrm{PL}$, and the members of the working group 1 . Sputum induction. Eur Respir J. 2002;20(Suppl. 37):S3-8.

16. Popov TA, Pizzichini MMM, Pizzichini E, Kolendowicz R, Punthakee $Z$, Dolovich J, et al. Some technical factors influencing the induction of sputum for cell analysis. Eur Respir J. 1995;8:559-65.

17. Twaddell SH, Gibson PG, Carty K, Woolley KL, Henry RL. Assessment of airway inflammation in children with acute asthma using induced sputum. Eur Respir J. 1996;9:2104-08.

18. Pizzichini MMM, Pizzichini E, Clelland L, Efthmiadis A, Mahony J, Dolovich J, et al. Sputum in severe exacerbations of asthma. kinetics of inflammatory indices after prednisone treatment. Am J Respir Crit Care Med. 1997;155:1501-6.

19. Fahy JV, Boushey HA, Lazarus SC, Mauger EA, Cherniack EM, Chinchilli VM, et al. Safety and reproducibility of sputum induction in asthmatic subjects in a multicenter study. Am J Respir Crit Care Med. 2001;163:1470-5.

20. Holz O, Kips J, Magnussen $\mathrm{H}$. Update on sputum methodology. Eur Respir J. 2000;16:355-9.

21. Gershman NH, Liu H, Wong HH, Liu J, Fahy JV. Fractional analysis of sequential induced sputum samples during sputum induction: evidence that different lung compartments are sampled at different time points. J Allergy Clin Immunol. 1999; 104:322-32.

22. Efthimiadis A, Jayaram L, Weston S, Carruthers S, Hargreave FE. Induced sputum: time from expectoration to processing. Eur Respir J. 2002;19:706-8.

23. Gershman NH, Wong HH, Liu JT, Mahlmeister MJ, Fahy JV. Comparison of two methods of collecting induced sputum in asthmatic subjects. Eur Respir J. 1996;9:2448-53.

24. Efthimiadis A, Spanevello A, Hammid Q, Kelly MM, Linden M, Louis $\mathrm{R}$ et al. Methods of sputum processing for cell counts, immunocytochemistry and in situ hybridisation. Eur Respir J. 2002;20(Suppl. 37):S19-S23.

25. Cai Y, Carty K, Henry RL, Gibson PG. Persistence of sputum eosinophilia in children with controlled asthma when compared with healthy children. Eur Respir J. 1998;11:848-53.

26. Gibson PG, Norzila MZ, Fakes K, Simpson J, Henry RL. Pattern of airway inflammation and Its determinants in children with acute severe asthma. Pediatr Pulmonol. 1999;28:261-70.

27. Pavord ID. And the members of the Working Group 5. Clinical applications of assessment of airway inflammation using induced sputum. Eur Respir J. 2002;20(Suppl.):S40-3.

28. Gibson PG. Use of induced sputum to examine airway inflammation in childhood asthma. J Allergy Clin Immunol. 1998; 102(Suppl.):S100-1.

29. Green RH, Brightling CE, McKenna S. asthma Exacerbations and sputum eosinophil counts: a randomized controlled trial. Lancet. 2002;360:1715-21.

30. Pedersen S. Why does airway inflammation persist? Is it failure to treat early? Am J Respir Crit Care Med. 2000;161(Suppl.): S182-5.

31. Bartoli ML, Bacci E, Carnevali S, Cianchetti S, Dente FL, Di Franco A, et al. Clinical assessment of asthma severity partially corresponds to sputum eosinophilic airway inflammation. Respir Med. 2004;98:184-93.

32. Fuhlbrigge AL. Asthma severity and asthma control: symptoms, pulmonary function, and inflammatory markers. Curr Opin Pulm Med. $2004 ; 10: 1-6$. 
33. Sterk PJ, Hargreave FE, Kips JC, Inman MD, Louis R, Pizzichini MMM, et al. Clinical applications of assessment of airway inflammation using induced sputum. Eur Respir J. 2002;20(Suppl.):S40-3.

34. Gibson PG, Simpson JL, Hankin R, Powel H, Henry RL. Relationship between induced sputum eosinophils and the clinical pattern of childhood asthma. Thorax. 2003;58:116-21.
Correspondência:

Maria Helena Bussamra

Rua Girassol, 464/52

CEP 05433001 - São Paulo, SP

Tel.: (11) 9687.0269

Fax: (11) 3034.5472

E-mail: nena.ferreira@uol.com.br 